\title{
Simulasi Pengaruh Pengoperasian Filter Aktif Shunt Terhadap Kenaikan Efisiensi Transformator di RSUD Kabupaten Klungkung
}

\author{
A A Gede Agung Brama Dinanta, I Wayan Rinas, Anak Gede Maharta Pemayun \\ Program Studi Teknik Elektro, Fakultas Teknik,Universitas Udayana \\ Email : agungbrama09@gmail.com
}

\begin{abstract}
Abstrak
Tingginya tingkat harmonisa yang terdapat pada penggunaan energi listrik dapat menyebabkan kualitas daya sistem menjadi lebih buruk. Bentuk gelombang tegangan dan arus sistem terdistorsi menimbulkan terjadinya peningkatan losses sehingga berpengaruh terhadap efisiensi dari transformator. Dalam penelitian ini akan dilakukan analisis THD arus di RSUD Kabupaten Klungkung. Hasil simulasi akan dibandingkan dengan standar IEEE 519-2014 pada kondisi existing dan kondisi saat pengoperasian filter aktif shunt, juga dilakukan analisa losses sebelum dan sesudah terpengaruh harmonisa. Hasil analisis Losses kondisi existing adalah losses Phasa R 2,310 kW, Phasa S 2,363 kW, Phasa T 2,285 kW. Simulasi pengoperasian filter aktif shunt didapat losses untuk phasa R 2,141 Kw, Phasa S 2,158 kW, Phasa T 2,142 Kw. Sehingga losses total pada saat existing sebesar 6,958 kW dan dan setelah di pasang filter aktif losses totalnya sebesar 6,441 kW. Tingkat efisiensi transformator di RSUD Kabupaten Klungkung pada saat existing sebesar 96,18\% dan setelah dipasang filter aktif shunt efisiensinya sebesar 96,46\%.
\end{abstract}

Kata Kunci : Harmonisa, THDi, filter aktif shunt, Losses dan Effisiensi

The high level of harmonics found in the use of electrical energy can cause the system's power quality to get worse. the voltage and current waveforms of a distorted system give rise to an increase in losses that affect the efficiency of the transformer. In this study a current THD analysis will be carried out in Klungkung District Hospital. The simulation results will be compared with the IEEE 519-2014 standard in theconditions existing and the conditions at the operation of the shunt active ilter,analysis is also carried out losses before and after the harmonics are affected. The results of theanalysis of Losses the existing conditions are losses of Phase R2.310 kW, Phase S of $2.363 \mathrm{~kW}$, Phase T of $2.285 \mathrm{~kW}$. The operating simulation of activefilters shunt obtained losses for phase R 2,141 Kw, Phases S 2,158 kW, Phase T 2,142 kW, so that the losses totalat the time of the existing amounted to $6,958 \mathrm{~kW}$ and after installation of active filters losses were total6,441 kW. The level of efficiency transformer in hospitals whenKlungkung existing amounted to $96.18 \%$ and after being fittedactive filter shuntefficiency of $96.46 \%$.

Keywords: Harmonics, THDi, active shunt filters, Losses and Efficiency

\section{Pendahuluan}

Perkembangan teknologi yang sangat cepat akan membawa dampak dalam kehidupan manusia. Peralatan listrik yang saat ini sering dikembangkan kebanyakan berbasis mikro elektronik. Peralatan jenis ini merupakan jenis beban non linier, beban nonlinier memiliki bentuk gelombang yang tidak sinusoidal karena telah terdistorsi oleh harmonisa yang ditimbulkan akibat penggunaan perangkat elektronika daya seperti diode, thyristor, mosfet.[1]

Tingginya tingkat harmonisa yang terdapat pada penggunaan energi listrik dapat 
menyebabkan kualitas daya sistem menjadi lebih buruk. bentuk gelombang egangan dan arus sistem terdistorsi, rugi-rugi daya pada sistem meningkat, pemanasan transformator yang berlebih, peningkatan arus netral sistem yang menyebabkan beban lebih pada konduktor netral, dan penggunaan energi listrik menjadi tidak efisien. [2]

Filter harmonisa merupakan suatu teknologi elektronika daya untuk menghasilkan komponen arus spesifik yang bertujuan untuk meredam arus harmonisa yang dihasilkan oleh beban non linier. [3]

Beban nonlinier memiliki bentuk gelombang yang tidak sinusoidal karena telah terdistorsi oleh harmonisa yang ditimbulkan akibat penggunaan perangkat static switching seperti diode, thyristor, mosfet yang banyak digunakan pada peralatan rumah sakit seperti komputer, pendingin ruangan (AC), mikroskop,dialyzer, hematology analyzer, blood analyzer, dan berbagai peralatan medis lainnya.[4]

Peralatan - peralatan yang banyak digunakan di RSUD Klungkung yaitu memiliki mesin anestesi (alat ini digunakan saat oprasi), lampu oprasi, mesin EKG (alat pemeriksa jantung), AC (Air Conditioner), dan lain sebagainya diklasifikasikan sebagai beban nonlinier. Karena banyaknya beban-beban nonlinier yang dioperasikan, maka dapat dipastikan akan memungkinkan terjadinya distorsi harmonisa pada utility listriknya. Berdasarkan pengukuran trasformator awal yang dilakukan pada bulan Juli tahun 2018 di RSUD Klungkung. Setelah dilakukan analisis THD arus masing-masing phasa diperoleh nilai : untuk phasa R sebesar 16,66\%, phasa $\mathrm{S}$ sebesar $16,47 \%$ dan phasa $T$ sebesar 13,00\%. Berdasarkan standar IEEE 519-2014 bahwa $\mathrm{I}_{\text {THD }}$ harus dibawah $8 \%$ sehingga diketahui bahwa $I_{T H D}$ pada transformator melebihi standar.

Berdasarkan masalah tersebut diatas, maka pada skripsi ini akan dilakukan simulasi pengaruh pengoperasian filter aktif shunt terhadap kenaikan efisiensi transformator di RSUD Klungkung dengan menghitung THD arus dan mempergunakan program MATLAB, sehingga dapat diketahui distorsi daya dan perubahan rugi-rugi daya.

\section{Tinjauan Pustaka}

\section{a. Kualitas daya listrik}

Kualitas daya listrik juga bisadisamakan sebagai hubungan dari daya listrik dengan peralatan listrik. Jika peralatan listrik bekerja secara tepat dan handal tanpa mengalami tekanan dan kerugian dapat dikatakan peralatan listrik tersebut mempunyai kualitas daya yang baik sebaliknya ketika perlengkapan listrik gagal fungsi (malfunction), kurang handal atau mengalami kerugian pada saat penggunaan normal, dapat dikatakan bahwa peralatan tersebut memiliki kualitas daya yang buruk. Pada dasarnya, tegangan disuplai dalam bentuk sinusoidal yang mempunyai amplitudo dan frekuensi yang sesuai dengan standar (pada umumnya) atau spesifikasi sistem.[3]

\section{b. Harmonisa pada sistem tenaga listrik}

Harmonisa pada suatu sistem kelistrikan merupakan salah satu penyebab yang mempengaruh kualitas daya listrik. Pengaruh adanya harmonisa sangat dominan karena bersifat permanen dan menyebabkan terbentuknya gelombang rekuensi jtinggi ( kelipatan dari frekuens fundamental, misal: $100 \mathrm{~Hz}, \quad 150 \mathrm{~Hz}, \quad 200 \mathrm{~Hz}, \quad 300 \mathrm{~Hz}$, dan seterusnya). Hal ini dapat mengganggui sistem kelistrikan pada frekuensi fundamentalnya yaitu $50 / 60 \mathrm{~Hz}$, sehingga bentuk gelombang arus maupun tegangan yang idealnya adalah sinusoidal murni akan menjadiiicacat akibat distorsi harmonisa yang terjadi.[3]

\section{Beban linier}

Beban linieriiiadalah bebaniiiyang komponen arusnya proporsiona terhadap tegangannya. Terdapat hubungan yang linier antara iarus dan tegangan sehingga bentuk gelombang arus akan sama dengan jbentuk gelombang 
tegangannya, seperti terlihat pada Gambar $1 \mathrm{di}$ bawah ini. Beban linier menyerap arus sinusoidal bila disuplai oleh

tegangan sinusoidal. Contoh beban linier antara lain motor Istrik, pemanas, lampu pijar, dan lainnya [4]

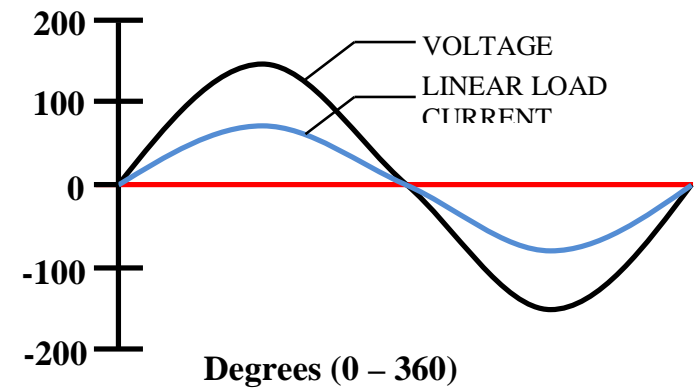

Gambar 1 Bentuk gelombang arus dan tegangan pada beban linier

Sumber : Dugan

\section{Beban nonlinier}

Beban yang komponen larusnya tidak proporsionali terhadap komponen tegangannya, sehingga bentuk gelombang arusnya tidak sama dengan bentuk gelombang tegangannya. Tidak terdapat hubungan yang linier antara arus dan tegangan. Beban nonlinier menyerap arus non sinusoidal demikian juga arus harmonik, walaupun disuplai oleh tegangan sinusoidal. Sepert Gambar 2 di bawah ini .[4]

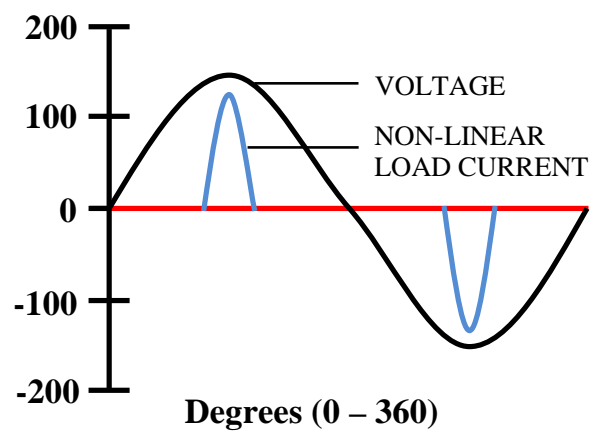

Gambar 2. Bentuk gelombang arus dan tegangan pada beban nonlinier Sumber : Dugan

\section{THD (Total Harmonic Distortion)}

THD adalah ukuran dari nilai efektif bentuk gelombang yang terdistorsi dari komponen harmonisa.THD juga dapat didefinisikan sebagai rasio antara nila RMS dari komponen harmonisa dan nilai RMS dari fundamental. Harmonik tegangan atau arus diukur dari besarnya masingmasing komponen harmonik terhadap komponen dasarnya dinyatakan dalam prosennya. Untuk memperoleh suatu parameter yang dipakai untuk menilai harmonik tersebut dipakai THD [3]. THD dinyatakan dengan persamaan sebagai berikut, yaitu:

$$
T H D=\frac{\sqrt{\sum_{h>1}^{h_{\text {max }}} M_{h}{ }^{2}}}{M_{1}}
$$

Dimana $M_{h}$ adalah nilai rms komponen THD juga dapat dinyatakan dalam persamaan lain yaitu :

$$
T H D=\frac{1}{U_{1}}\left(\sum_{n=2}^{k} U_{n}^{2}\right)^{\frac{1}{2}}
$$

persentase jumlah total tegangan yang terdistorsi oleh harmonisa dan $\% I_{T H D}$ adalah persentasi jumlah total arus yang terdistorsi oleh harmonisa. Rumus tegangan harmonisa $\left(V_{h}\right)$ dapat dijelaskan sebagai rasio dari tegangan sistem nominal $\left(\mathrm{V}_{\mathrm{s}}\right)$ dalam persen:

$$
\% V_{h}=\frac{V_{h}}{V_{s}} \times 100=h \frac{I_{h}}{I_{s c}} \times 100
$$

(4)

$$
\% V_{h}=\frac{\left(I_{h} / I_{i}\right)}{\left(I_{s c} / I_{i}\right)} \times 100
$$

$$
\begin{aligned}
& \text { dimana: } V_{h}=\text { Tegangan harmonisa } \\
& V_{s}=\text { Tegangan sistem } \\
& \mathrm{I}_{\mathrm{h}}=\text { Arus harmonisa } \\
& \mathrm{I}_{\mathrm{sc}}=\text { Arus short circuit } \\
& \mathrm{I}_{\mathrm{sc}} / \mathrm{I}_{\mathrm{i}}=\text { Rasio yang ada pada tabel Limit } \\
& \quad \text { Distorsi Arus Harmonisa } \\
& \mathrm{I}_{\mathrm{i}}=\text { Arus yang mengambil daya beban }
\end{aligned}
$$

Total Harmonic Distortion ( THD ) pada arus didefinisikan: 


$$
I_{T H D}=\frac{\sum_{h=1}^{\infty} \sqrt{I_{h}{ }^{2}}}{I_{i}}
$$

(5)

\section{Standar Harmonisa}

Untuk memenuhi kebutuhan standarisasi IEEE telah mengeluarkan IEEE Std. 519- 2014 [5].

Ada dua kriteria yang digunakan untuk mengevaluasi distorsi harmonisa, yaitu batasan untuk harmonisa arus dan tegangan. IEEE telah menetapkan standar pada Point of Common Coupling $(P C C)$ seperti pada Tabel 1 dan Tabel 2:

Tabel 1 Batas distorsi tegangan

\begin{tabular}{|c|c|c|}
\hline BusVoltage at PCC & $\begin{array}{c}\text { Individual } \\
\text { Voltage } \\
\text { Distortion } \\
(\%)\end{array}$ & $\begin{array}{c}\text { Total harmonic } \\
\text { distortion } \\
\text { THD }(\%)\end{array}$ \\
\hline $\mathrm{V} \leq 1.0 \mathrm{Kv}$ & 5.0 & 8.0 \\
\hline $1 \mathrm{kV}<\mathrm{V}<69 \mathrm{Kv}$ & 3.0 & 5.0 \\
\hline $69 \mathrm{kV}<\mathrm{V} \leq 161 \mathrm{kV}$ & 1.5 & 2.5 \\
\hline $161 \mathrm{kV}<\mathrm{V}$ & 1.0 & 1.5 \\
\hline
\end{tabular}

Tabel 2. Batas Distorsi Arus Harmonik dengan rating tegangan $120 \mathrm{~V}$ hingga $69 \mathrm{kV}$

\begin{tabular}{|c|c|c|c|c|c|c|}
\hline \multicolumn{6}{|c|}{ Maximum harmonic current distortion in percent of $\mathrm{I}_{\mathrm{L}}$} \\
\hline \multicolumn{6}{|c|}{ Individual harmonic ordee (odd harmonic) } \\
\hline $\mathrm{I}_{\mathrm{SC}} / \mathrm{I}_{\mathrm{L}}$ & $3 \leq \mathrm{h} \leq 11$ & $11 \leq \mathrm{h} \leq 17$ & $\begin{array}{c}17 \leq \mathrm{h} \\
\leq 23\end{array}$ & $\begin{array}{c}23 \leq \mathrm{h} \\
\leq 35\end{array}$ & $\begin{array}{c}35 \leq \\
\mathrm{h} \leq 50\end{array}$ & $\mathrm{THD}$ \\
\hline$<20$ & 4.0 & 2.0 & 1.5 & 0.6 & 0.3 & 5.0 \\
\hline $\begin{array}{c}20< \\
50\end{array}$ & 7.0 & 3.5 & 2.5 & 1.0 & 0.5 & 8.0 \\
\hline $\begin{array}{c}50< \\
100\end{array}$ & 10.0 & 4.5 & 4.0 & 1.5 & 0.7 & 12.0 \\
\hline $\begin{array}{c}100 \\
<1000\end{array}$ & 12.0 & 5.5 & 5.0 & 2.0 & 1.0 & 15.0 \\
\hline$>1000$ & 15.0 & 7.0 & 6.0 & 2.5 & 1.4 & 20.0 \\
\hline
\end{tabular}

THDiarusiharmonisajurutan genapjjdibatasi $25 \%$ darijjharmonisajurutan ganjil di atas. Distorsi arusjyangjdisebabkanjjsebuahjjpenyearahjseteng ahjjgelombang dc tidak diizinkan atau tidak termasuk pada tabel di atas

\section{c. Perhitungan Losses pada Transfo Akibat Harmonisa}

Losses suatu transfo secara teknis dapat disebut sebagai load loss $\left(\mathrm{P}_{\mathrm{LL}}\right)$. Terdapat dua komponen yang dipertimbangkan.

$$
Z_{S}=\frac{k V \varphi^{2}}{M V A 3 \varphi} \times Z(\%)
$$

(6)

$I^{2} R$ loss adalah rugi tembaga yang proporsional, sedangkan $P_{E C}$ dapat dihitung dengan persamaan berikut [3]

$$
P_{E C}=K_{E C} \times I^{2} \times h^{2}
$$

dimana : $\mathrm{K}_{\mathrm{EC}}=$ Proportionality Constant

Dalam satuan per unit (p.u), $P_{L L}$ dapat dihitung dengan menggunakan persamaan berikut ini [3]

(8)

$$
P_{L L}=\sum I_{h}{ }^{2}+\left(\sum I_{h}{ }^{2} \times h^{2}\right) \times P_{E C-R}(p . u)
$$

dimana :

$$
\begin{aligned}
& P_{E C-R}=\text { Eddy Current Loss Factor } \\
& h=\text { Harmonisa (\%) } \\
& I_{h}=\text { Arus Harmonisa (A) } \\
& \sum I_{h}{ }^{2} \text { merupakan komponen dari rugi }
\end{aligned}
$$
tembaga yang dinyatakan dalam satuan per unit (p.u), sedangkan $\left(\sum I_{h}{ }^{2} \times h^{2}\right) \times P_{E C-R}$ merupakan faktor rugi arus eddy di bawah kondisi normal yang dinyatakan dalam satuan per unit (p.u). Faktor $\mathrm{P}_{\mathrm{EC}}$ dapat dilihat pada Tabel 3

Tabel 3 Typical Values of $P_{E C-R .}$

\begin{tabular}{|c|c|c|c|}
\hline Type & MVA & Voltage & $\begin{array}{c}\mathbf{P}_{\text {EC-R }} \\
(\%)\end{array}$ \\
\hline \multirow{4}{*}{ Dry } & $\leq 1$ & - & $3-8$ \\
\cline { 2 - 4 } & $\leq 1,5$ & $5 \mathrm{kV}$ (High Voltage) & $12-20$ \\
\cline { 2 - 4 } & $\leq 1,5$ & $\begin{array}{c}15 \mathrm{kV} \text { (Hight } \\
\text { Voltage) }\end{array}$ & $9-15$ \\
\hline \multirow{3}{*}{$\begin{array}{c}\text { Oil- } \\
\text { filled }\end{array}$} & $\begin{array}{c}2,5- \\
5\end{array}$ & $\begin{array}{c}480 \text { V (Low } \\
\text { Voltage) }\end{array}$ & 1 \\
\cline { 2 - 4 } & $>5$ & $\begin{array}{c}480 \text { V (Low } \\
\text { Voltage) }\end{array}$ & $1-5$ \\
\cline { 2 - 4 } & $>50$ Voltage) & $9-15$ \\
\hline
\end{tabular}

Sumber : [3]

\section{d. Perhitungan Efisiensi transformator}

Suatu transformator memiliki tingkat efisiensi yang sangat tinggi hingga mencapai $99,5 \%$ atau lebih. Real power losses (Rugi-rugi daya nyata) biasanya kurang dari 0,5\% dari kVA rating transformator pada saat beban puncak 
1) Efisiensi Transformator: Tingkat efisiensi suatu transformator dapat dihitung dengan menggunakan persamaan sebagai berikut :

$\%$ Efficiency $=\left[1-\frac{\sum \text { Rugi Total }}{\text { Daya Input }}\right] \times 100 \%$

\section{Metode Penelitian}

\subsection{Teknik Pengumpulan Data}

Penelitian ini dilakukan di Rumah Sakit Umum Daerah (RSUD) Kabupaten Klungkung yang berlokasi di Jalan Flamboyan no.40.

Data yang diperoleh dalam penelitian ini dianalisis dengan prosedur yaitu pertama membuat pemodelan sistem transformator tiga phasa di RSUD Kabupaten Klungkung pada simulink MATLAB, Simulasi dilakukan dengan menggunakan FFT tools. FFT merupakan metode analisis sinyal yang handal dimana dapat digunakan untuk menganalisis distortion.

Simulasi yang dilakukan pada Simulink MATLAB dengan desain pemodelan yang dirancang merupakan sistem 4 kawat dimana terdiri dari 3 kawat phasa dan 1 kawat netral.

\subsection{Alur Analisis}




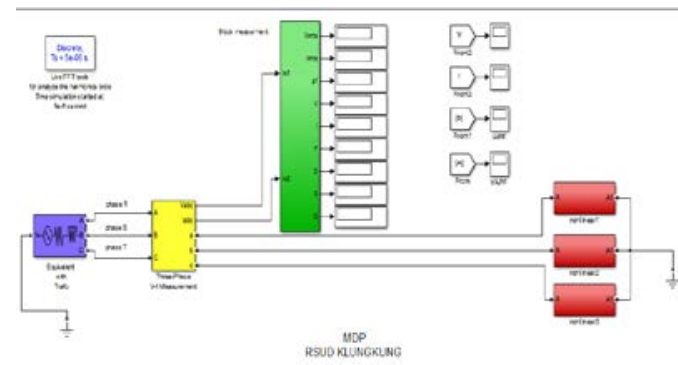

Gambar 4. (Pemodelan Sistem tanpa filter)

Model simulasi gambar 5 ini merupakan pemodelan system menggunakan filter aktif shunt untuk melakukan simulasi pada MATLAB

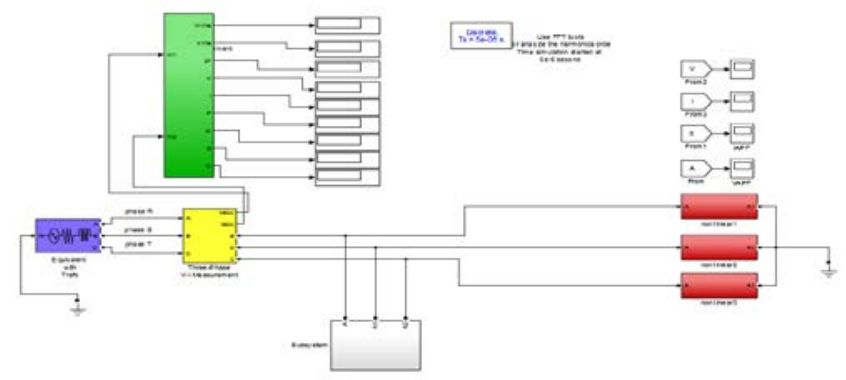

Gambar 5.( Pemodelan Sistem menggunakan filter aktif shunt)

\section{b. Simulasi THD Arus pada kondisi existing}

Pada simulasi ini akan dilakukan simulasi menggunakan model seperti gambar 4. Simulasi dilakukan untuk masing - masing phasa MDP RSUD Kabupaten Klungkung, dan akan terlihat $T H D_{i}$, bentuk output gelombang arus, orde harmonisa, dan arus.

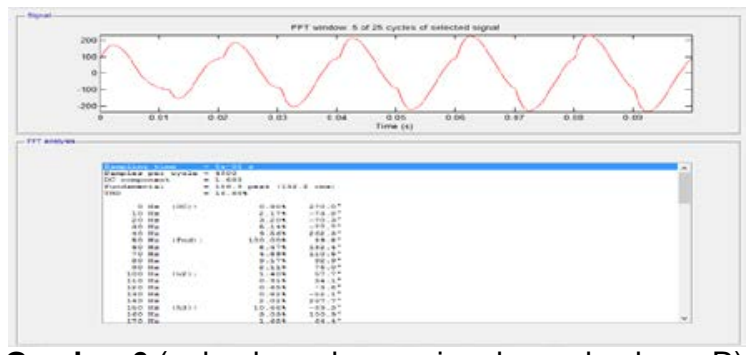

Gambar 6 (gelombang harmonisa dan orde phasa R)

Dengan cara yang sama kita dapat mensimulasikan $T H D_{i}$ untuk mendapatkan nilai $T H D_{i} \quad$ masing-masing phasa dan
THD ${ }_{i}$ maksimum menurut IEEE Std 519-2014 seperti diperlihatkan pada tabel 4 :

Tabel.4 Prosentase $T H D_{i}$ perphasa kondisi exiting

\begin{tabular}{|c|c|c|c|c|}
\hline MDP & Phasa & $\begin{array}{c}\mathrm{THD}_{\mathrm{i}} \\
(\%)\end{array}$ & $\begin{array}{c}\mathrm{THD}_{\text {imax }} \\
(\%)\end{array}$ & Keterangan \\
\hline \multirow{2}{*}{$\begin{array}{c}\text { MDP } \\
\text { RSUD } \\
\text { Klungkung }\end{array}$} & $\mathrm{R}$ & 16.66 & 8 & Tdk sesuai standar \\
\cline { 2 - 5 } & $\mathrm{T}$ & 13.00 & 8 & Tdk sesuai standar \\
\cline { 2 - 5 }
\end{tabular}

Dari hasil simulasi $\mathrm{THD}_{i}$ yang dilakukan, didapatkan nilai presentase $\mathrm{THD}_{\mathrm{i}}$ Phasa $\mathrm{R}$, Phasa S dan T tidak memenuhi standar.

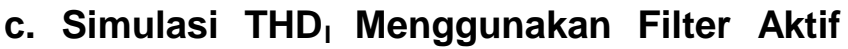 Shunt}

Pada simulasi ini akan dilakukan simulasi menggunakan model seperti gambar 6 . Simulasi dilakukan untuk masing - masing phasa MDP RSUD Kabupaten Klungkung, dan akan terlihat $T H D_{i}$, bentuk output gelombang arus dan tegangan yang terdistorsi, orde harmonisa, dan arus.

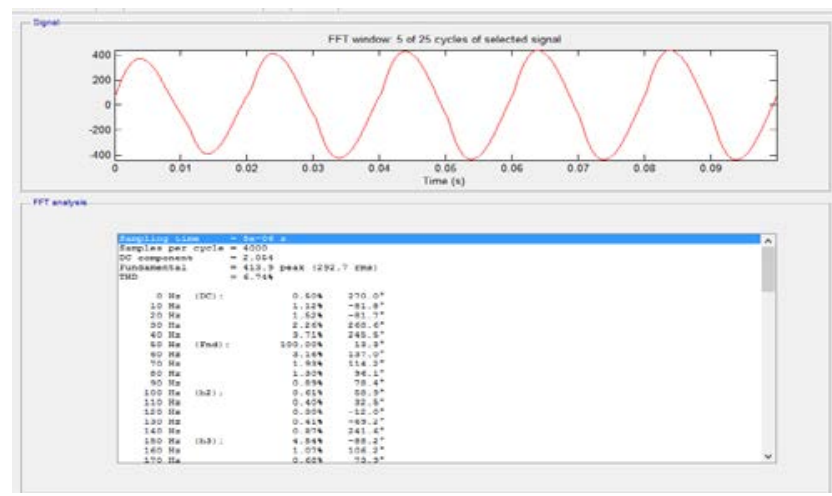

Gambar 7 (gelombang harmonisa dan orde phasa R)

Tabel.5 Prosentase $T H D_{i}$ perphasa kondisi exiting

\begin{tabular}{|c|c|c|c|c|}
\hline MDP & Phasa & $\begin{array}{c}\mathrm{THD}_{\mathrm{i}} \\
(\%)\end{array}$ & $\begin{array}{c}\mathrm{THD}_{\text {imax }} \\
(\%)\end{array}$ & Keterangan \\
\hline \multirow{2}{*}{$\begin{array}{c}\text { MDP } \\
\text { RSUD } \\
\text { Klungkung }\end{array}$} & $\mathrm{R}$ & 6.74 & 8 & Sesuai standar \\
\cline { 2 - 5 } & $\mathrm{S}$ & 7.82 & 8 & Sesuai standar \\
\cline { 2 - 5 } & $\mathrm{T}$ & 6.51 & 8 & Sesuai standar \\
\hline
\end{tabular}

Setelah dilakukan simulasi dengan menambahkan filter aktif shunt, didapatkan hasil simulasi THDi pada MDP RSUD Klungkung 
sudah memenuhi standar IEEE 529-2014 seperti diperlihatkan pada table 5 di atas.

\section{d. Analisa Losses}

\section{Analisis losses sebelum terpengaruh harmonisa}

Rugi-rugi trafo pada kondisi tanpa besarannya telah ditentukan oleh. Sesuai SPLN 50: 1997 (tentang spesifikasi transformator distribusi), maka dapat ditentukan nilai losses pada trafo 200 kVA seperti dibawah ini:

Total losses (dalam kW) $=P_{c u}+P_{i}$

$$
\begin{aligned}
& =2500+480 \\
& =2980 \mathrm{~W}=2,98 \mathrm{~kW}
\end{aligned}
$$

Karena $\cos \varphi$ adalah 0.9 , maka rugi-rugi dalam kVA :

Lossesnya $=2,98 \mathrm{Kw} / 0,9=3,31 \mathrm{kVA}$

\section{Analisa Losses pada kondisi existing.}

Langkah pertama adalah menentukan $P$ base 1ф, mencari arus harmonisa orde ganjil (orde 1 - orde 19), sehingga Arus harmonisa $\left(I_{h}\right)$ dalam pu untuk setiap phasa dapat dihitung dengan persamaan (6) :

$$
\begin{aligned}
& I_{h_{1} \text { phasaR }}(p . u)=\frac{I_{h 1}}{I_{1}}=\frac{132,2}{132,2}=1,000(\text { p.u }) \\
& I_{h_{3} \text { phasar }}(p . u)=\frac{I_{h 3}}{I_{1}}=\frac{14,093}{132,2}=0,1066(\text { p.u })
\end{aligned}
$$

Berdasarkan nilai $I_{\mathrm{h}}$ tiap orde seperti di atas, maka nilai $\mathrm{I}_{\mathrm{h}}^{2}$ dan $\mathrm{I}_{\mathrm{h}}{ }^{2} \times \mathrm{h}^{2}$ setiap phasa dapat ditentukan dalam pu.

Berdasarkan hasil perhitungan harmonisa dari orde-1 sampai orde-19 maka dapat dihitung loadloss $\left(P_{L L}\right)$ untuk setiap phasanya menggunakan persamaan (8). Nilai $P_{E C-R}$ untuk transformator dengan tegangan skunder $400 \mathrm{~V}$ diketahui sebesar 1\%. Sehingga hasil perhitungan $\mathrm{P}_{L L}$ dalam pu untuk masing-masing phasa dapat dilihat pada Table 6 .

\begin{tabular}{|c|c|}
\hline Tabel $6 P_{L L}$ dalam satua $p u$ \\
\hline Phasa & $\mathrm{P}_{\mathrm{LL}}$ (p.u) \\
\hline $\mathrm{R}$ & 0,02196 \\
\hline
\end{tabular}

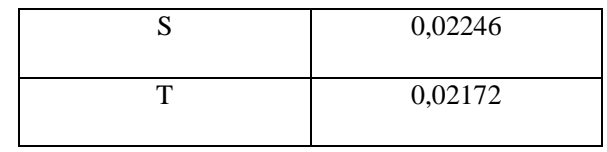

Untuk mendapatkan $P_{L L}$ dalam dikalikan dengan $P$ base $1 \phi$, seperti Table 7 berikut.

Tabel 7 Loadloss dalam masing-masing phasa

\begin{tabular}{|c|c|c|c|}
\hline Phasa & Losses (p.u) & $\begin{array}{c}\mathrm{P}_{\text {Base 1 Phase }} \\
(\mathrm{kW})\end{array}$ & Losses (kW) \\
\hline $\mathrm{R}$ & 0,02196 & 105,193 & 2,310 \\
\hline $\mathrm{S}$ & 0,02246 & 105,193 & 2,363 \\
\hline $\mathrm{T}$ & 0,02172 & 105,193 & 2,285 \\
\hline \multicolumn{3}{|c|}{ Total Losses } & 6,958 \\
\hline
\end{tabular}

\section{Analisa Losses dengan Mengoperasikan Filter Aktif}

Dengan cara yang sama seperti pada kondisi existing, maka $\mathrm{P}_{\mathrm{LL}}$ untuk kondisi pengoperasian Filter Aktif didapat seperti Table 8 :

Tabel 8 Loadloss dalam masing-masing phasa

\begin{tabular}{|c|c|c|c|}
\hline Phasa & $\begin{array}{c}\text { Losses } \\
(\mathbf{p . u})\end{array}$ & $\begin{array}{c}\mathbf{P}_{\text {Base 1 Phase }} \\
\mathbf{( k W )}\end{array}$ & $\begin{array}{c}\text { Losses } \\
\mathbf{( k W )}\end{array}$ \\
\hline $\mathrm{R}$ & 0,02036 & 105,193 & 2,141 \\
\hline $\mathrm{S}$ & 0,02051 & 105,193 & 2,158 \\
\hline $\mathrm{T}$ & 0,02036 & 105,193 & 2,142 \\
\hline \multicolumn{3}{|c|}{ Total Losses } & 6,441 \\
\hline
\end{tabular}

Tabel 9 Perbandingan Losses untuk kedua kondisi

\begin{tabular}{|c|c|}
\hline \multicolumn{1}{|c|}{ Deskripsi } & $\boldsymbol{P}_{\mathbf{L L}}(\mathbf{k W})$ \\
\hline$P_{L L}$ Harmonisa - kondisi exiting & 6,958 \\
\hline$P_{L L}$ Harmonisa - Filter aktif & 6,441 \\
\hline
\end{tabular}




\section{Kesimpulan}

Berdasarkan pembahasan yang telah diuraikan diatas tentang simulasi pengaruh pengoperasian filter aktif shunt terhadap kenaikan efisiensi transformator di RSUD Kabupaten Klungkung dapat disimpulkan :

1. Pada kondisi existing untuk rugi - rugi mengalami kenaikan losses sedangkan pada pemakian filter aktif mengalami penurunan. Untuk rugi - rugi daya, diperoleh hasil pada phasa $\mathrm{R}$ mengalami peningkatan losses sebesar $2.310 \mathrm{~kW}$, phasa $\mathrm{S} 2,363 \mathrm{~kW}$, dan phasa $\mathrm{T} 2,285 \mathrm{~kW}$, total losses dari ketiga phasa yaitu $6,958 \mathrm{~kW}$. Sedakangkan untuk rugi - rugi daya menggunakan filter aktif mengalami penurunan untuk phasa $\mathrm{R} 2,141$ $\mathrm{kW}$, phasa S 2,158 kW, phasa T 2,142 kW, total daya dari ketiga phasa yaitu $6,441 \mathrm{~kW}$.

2. Pada kondisi existing untuk efisiensi transforrmator yaitu mencapai 96,18\%. Namun setelah dipasangnya filter aktif shunt menyebabkan terjadinya kenaikan efisiensi sebesar 96,46\% pada transformator RSUD Klungkung. Jadi dapat disimpulkan bahwa semakin tinggi losses maka semakin rendah efisiensinya.

\section{References}

[1] Dugan, R.C., McGranaghan, M.F., Santoso, S., Beaty, H.W. 2004. Electrical Power System Quality-Second Edition. The McGraw-Hill.

[2] Harlow, J.H. 2004. Electric Power Engineering. United States of America : CRC Press

[3] Dugan, R.C., McGranaghan, M.F., Santoso, S., Beaty, H.W. 2004. Electrical Power System Quality-Second Edition. The McGraw-Hill.

[4] Dugan, R.C; Rizy. 2001. Harmonic Considerations for Electrical Distribution Feeders. National Technical Information Service, Report No. ORNL/Sub/81-95011/4 (Cooper Power Systems as Bulletin 87011,
"Electrical Power System Harmonics, Design Guide").

[5] IEEE Recommended Practices and Requirements for Harmonic Control in Electric Power Systems. IEEE Standard 5192014.

[6] Izhar. Metal. "Performance for Passive and Active Power Filter in Reducing Harmonics in the Distribution System", National Power \& Energy Conference (PECon) 2004, IEEE Proceedings, Kuala Lumpur, Malaysia, pp. 104-108, 2004.

[7] De La Rosa, F. C. 2006. Harmonics And Power System. United State of America : Taylor \&Francis Group.

[8] Ferracci, Ph. 2001. Power Quality. Cahier Technique Merlin Gerin no: 199. 